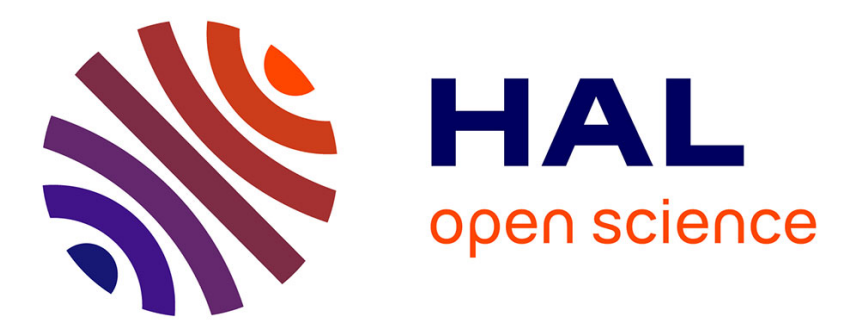

\title{
Assessment of the long-term performance of SCC incorporating different mineral admixtures in a magnesium sulphate environment
}

Hocine Siad, Mohamed Lachemi, Siham Kamali Bernard, Mustafa Sahmaran, Anwar Hossain

\section{To cite this version:}

Hocine Siad, Mohamed Lachemi, Siham Kamali Bernard, Mustafa Sahmaran, Anwar Hossain. Assessment of the long-term performance of SCC incorporating different mineral admixtures in a magnesium sulphate environment. Construction and Building Materials, 2015, 80, pp.141-154. 10.1016/j.conbuildmat.2015.01.067 . hal-01138079

\section{HAL Id: hal-01138079}

https://hal-insa-rennes.archives-ouvertes.fr/hal-01138079

Submitted on 1 Apr 2015

HAL is a multi-disciplinary open access archive for the deposit and dissemination of scientific research documents, whether they are published or not. The documents may come from teaching and research institutions in France or abroad, or from public or private research centers.
L'archive ouverte pluridisciplinaire HAL, est destinée au dépôt et à la diffusion de documents scientifiques de niveau recherche, publiés ou non, émanant des établissements d'enseignement et de recherche français ou étrangers, des laboratoires publics ou privés. 


\title{
Assessment of the Long-term Performance of SCC Incorporating Different Mineral Admixtures in a Magnesium Sulphate Environment
}

\author{
Hocine Siad $^{1,2, *}$, Mohamed Lachemi ${ }^{1}$, Siham Kamali Bernard ${ }^{3}$, Mustafa Sahmaran ${ }^{4}$, \\ Anwar Hossain ${ }^{1}$ \\ ${ }^{1}$ Department of Civil Engineering, Ryerson University, Toronto, ON, Canada. \\ ${ }^{2}$ Laboratory of Materials and Sustainable Development, Bouira University, Bouira, Algéria \\ ${ }^{3}$ Laboratory of Civil Engineering and Mechanical Engineering, Applied Sciences National \\ Institute, Rennes, France \\ ${ }^{4}$ Department of Civil Engineering, Gazi University, Ankara, Turkey
}

\begin{abstract}
The effects of mineral admixture type on the behaviour of self-consolidating concrete (SCC) in magnesium sulphate environments were investigated over the course of four years of exposure. Three mineral admixtures (limestone filler, fly ash and natural pozzolan) representing a wide range of compositions were used in the study. Twelve formulations covering three strength classes (30,50 and $70 \mathrm{MPa}$ ) and four concrete mixtures were studied. Mass loss with physical deterioration, and dimensional and compressive strength changes due to magnesium sulphate attack were determined through microstructural analysis. The sulphate profiles of sulphur, magnesium, silicon, calcium and aluminium elements were also quantified through analyses of the samples. A complementary analysis by phase assemblages was performed on the degraded layers of concrete specimens. These test results indicate that the mineral admixture type greatly affects the durability performance of SCC under magnesium sulphate exposure. Among the tested mineral admixtures, natural pozzolan showed better long-term durability performance in the magnesium sulphate environment. The interaction between vibrated concrete and SCC is related to the nature of the mineral admixtures.
\end{abstract}

Keywords: Self-consolidating concrete; mineral admixture; natural pozzolan, fly ash; limestone filler; magnesium sulphate attack.

* Corresponding author. Tel.: +15144511158

Email address: hcine_siad@yahoo.fr; hsiad@ryerson.ca 


\section{Introduction}

Self-consolidating concrete (SCC) is characterized by its ability to compact itself by means of its own weight, with little or no vibration and without segregation or bleeding. It fills all recesses, reinforcement spaces and voids, even in highly reinforced concrete members. Recently, this type of concrete has gained wide use in many countries. Because of the advantages it offers, SCC is increasingly being used in civil engineering structures such as substructures, infrastructure and industrial floors that are regularly subjected to aggressive environmental conditions.

External sulphates are highly soluble salts that are considered to be one of the major problems affecting concrete structures. The results of sulphate attack are generally related to the volume change, cracking and hence the deterioration of concrete. Magnesium sulphate $\left(\mathrm{MgSO}_{4}\right)$ is responsible for the fastest, most severe attacks on concrete [1]. According to Golop and Taylor [2], magnesium sulphate is more severe than sodium sulphate. Their spectrum media is wide, and they usually originate from underground water, soil, seawater or industrial wastewater. The magnesium sulphate reacts with double action, with the ions $\mathrm{SO}_{4}{ }^{2-}$ reacting with the aluminate (or portlandite) to form gypsum and ettringite. The ions $\mathrm{Mg}^{2+}$ may react with $\mathrm{OH}^{-}$to form brucite $\left[\mathrm{Mg}(\mathrm{OH})_{2}\right]$ or cause a partial replacement of calcium by magnesium in calcium Silicate Hydrate (C-S-H). The Magnesium Silicate Hydrate (M-S-H), thus formed, has no binder properties and the hydrated paste becomes soft and incoherent [3, 4].

Deterioration due to magnesium sulphate is a well-known occurrence in ordinary concrete, and there have been numerous studies conducted into its effects [5-9]. However, the composition of SCC is quite different than that of ordinary concrete. The mixture design of 
SCC usually incorporates an efficient high-range water-reducing admixture, possibly a viscosity-modifying admixture, controlled coarse aggregate volume fraction and a large amount of mineral admixture. The influence of the nature and volume of mineral admixture content in SCC appears to be fundamental to understanding the behavior of the material in a magnesium sulphate environment. However, there is very little information in the literature on the behavior of SCC under $\mathrm{MgSO}_{4}$ attack. Uysal and Sumer presented an experimental study on the influence of replacement of Portland cement with fly ash (FA), granulated blast furnace slag (GGBS), limestone powder (LP), basalt powder (BP) and marble powder (MP) on the magnesium sulphate attack durability of high-strength SCC [10]. The rate of attack was evaluated by visual examination and the reduction in compressive strength of samples immersed for 400 days in 10\% magnesium sulphate solution. According to the results of this study, incorporation of FA, GGBS, LP, BP and MP substantially improved the resistance of SCCs against $\mathrm{MgSO}_{4}$ attack. In a recent publication, Hassan et al. studied the assessment of magnesium sulphate attack on SCC containing FA, rice husk ash (RHA), and GGBS, with cement replacement levels of 5 to $15 \%$ [11]. Specimens were immersed in $5 \% \mathrm{MgSO}_{4}$ solution after seven days of curing. Compressive strength, length change, and mass loss were investigated over 118 days. Results of this study showed that adding FA, RHA, and GGBS to SCC improves its resistance to magnesium sulphate attack. These studies reveal the need for further comprehensive studies on the assessment of SCC incorporating high volumes of mineral admixtures under magnesium sulphate attack, especially for a long-term exposure period.

This paper presents a detailed mechanical, physical and microstructural study into the effects of strength class and nature of mineral admixture on the behavior of SCC in a magnesium sulphate environment. Twelve concrete mixtures with three strength classes were produced 
for the study. Three typical mineral admixtures (i.e., fly ash, natural pozzolan and limestone filler) were used in the production of the SCC mixtures, representing a wide range of chemical compositions. Ordinary concrete mixtures (OC) with similar strength grades were also produced for comparison purposes. The degree of magnesium sulphate attack was evaluated by visual inspection and by assessing mass change, dimensional variation and compressive strength change of concrete specimens immersed in the reference medium (fresh water) and in 5\% magnesium sulphate solution for 1440 days (4 years). Microstructural changes within the different layers of degraded samples were analyzed using scanning electron microscopy (SEM) and X-ray diffraction (XRD) analyses. Sulphate profiles were performed with backscattered electron imaging from the surface towards the core of the concrete samples, avoiding aggregates. The mechanisms of damage were studied using a microanalysis graphical treatment of the infected and uninfected zones [12].

\section{Experimental program}

\subsection{Materials}

Portland cement CEM I-52.5, complying with European Standards EN 197-01 [13] (similar to ASTM C150 Type I cement [14]), was used as part of the cementitious materials in the production of SCC. Siliceous round sand with a maximum grain size of $4 \mathrm{~mm}$ and crushed silico-calcareous rocks with $12.5 \mathrm{~mm}$ maximum size were used as fine and coarse aggregates. The specific gravity and water absorption properties of round sand and crushed rocks were $2.6 \%$ and $1.2 \%$, and 2.66 and $0.5 \%$, respectively. Three types of mineral admixtures were used in the SCC mixtures: a limestone filler characterized by its high degree of fineness, a natural pozzolan from a volcanic deposit site, and a silico-aluminate Class-F fly ash. The superplasticizer (SP) used was an acrylic copolymer with a density of 1.06 and chloride ion 
content of $\leq 0.1 \%$. Table 1 describes the various physical and chemical characteristics of Portland cement and the mineral admixtures used in this study.

\subsection{Mixture proportions}

Four concrete recipes [ordinary concrete (OC), SCC with limestone filler (SCCLF), SCC with natural pozzolan (SCCPZ) and SCC with fly ash (SCCFA)] (12 concrete mixtures in total) were prepared, covering three strength classes (30 MPa, $50 \mathrm{MPa}$, and $>70 \mathrm{MPa}$ ). All of the various data related to the materials were taken into account for determining the SCC mix design using Bétonlab-Pro software [17]. Bétonlab-Pro combines several behavioural models calibrated from a wide range of concrete types, with the granular structure described by the compressible stacking model.

A fixed amount of binder (cement + mineral admixtures) equal to $520 \mathrm{~kg} / \mathrm{m}^{3}$ was selected. In each strength class, the concretes were formulated from the same components, with the same granular skeleton and constant water to binder (W/B) ratio. A comparison was then carried out using the same mechanical strength. The amount of superplasticizer was selected to obtain a slump flow as close to $670 \pm 20 \mathrm{~mm}$ as possible for all SCC mixtures. In order to get the same strength classes as the SCC, the OC formulation was realised using the Dreux-Gorisse method [18]. Table 2 gives the mixture proportions of the concretes investigated. As seen in the table, the mixtures are labeled based on their ingredients; for example, mixture SCC70LF had a compressive strength class of $70 \mathrm{MPa}$ and contained limestone filler. 


\subsection{Specimen preparation and testing}

Compressive strength and mass changes before and after immersion in the magnesium sulphate solution were monitored on $10 \times 10 \times 10 \mathrm{~cm}$ concrete cube specimens. Prismatic specimens with $7 \times 7 \times 28 \mathrm{~cm}$ dimensions were prepared to determine expansion amount after immersion. All specimens were demoulded after 24 hours and cured in a controlled chamber at $20^{\circ} \mathrm{C}$ and $95 \%$ relative humidity.

Slump-flow, L-box, V-funnel and air content tests were conducted in the fresh state to determine the properties of SCC in accordance with the tests recommended by the AFGC [19]. In the hardened state, after 28 days of curing, the initial mass, compressive strength and length of the specimens were determined before immersion in the sulphate solution. Two mediums were used for immersion: a fresh water tank (reference medium) and a water tank containing 5\% magnesium sulphate solution. The temperature of the solution was

maintained at $22 \pm 2{ }^{\circ} \mathrm{C}$. The testing procedure was conducted according to the ASTM C101204 [20] and the method outlined by Mehta [21]. The $\mathrm{pH}$ of the sulphate solution was maintained within a range of 6.0-8.0 by adding a suitable amount of sulphuric acid solution (0.1 $\mathrm{N} \mathrm{H}_{2} \mathrm{SO}_{4}$ ). In addition, the aggressive solutions were totally renewed every eight weeks. Samples were immersed for four years in the magnesium sulphate and fresh water solutions. To evaluate the effect of the various mineral admixtures on the durability of SCC exposed to magnesium sulphate solution, visual (photos), mechanical (compressive strength), physical (change of mass and length), and mineralogical (XRD) investigations were performed. Chemical and microstructural studies were also carried out using SEM coupled to EDS and microanalyses of polished surfaces. 


\section{Experimental results}

\subsection{Concrete properties in fresh state and compressive strength before immersion}

Table 3 presents the workability and basic mechanical properties of twelve SCC mixtures. The results of the SCC mixtures listed in Table 3 can be interpreted according to the limits of the standard for SCC tests recommended by the AFGC [19]. The SCC mixtures had good filling ability with a slump-flow equal to $670 \pm 20 \mathrm{~mm}$ and V-funnel flow times between 5.8 and 7 seconds. All SCC mixtures showed acceptable passing ability based on L-box and fillbox results, which ranged between 0.80 and 0.90 and $79 \%$ and $96.2 \%$, respectively.

When seven-day compressive strength test results were compared, a significant difference between SCCLF and other concretes was observed. The improved strength of SCCLF at an early age can be attributed to the formation of calcium carboaluminates hydrate, which led to a decrease in the total porosity and accelerated the hydration rate of the cement paste [22]. From the 28-day test results, the compressive strength values were closer to the targeted strength classes (30, 50 and $70 \mathrm{MPa}$ ), a result that confirms the reliability of the method used on the design of the different mixtures.

\subsection{Magnesium sulphate attack}

\subsubsection{Change of mass}

Mass change results for specimens immersed in 5\% magnesium sulphate solutions are shown in Figure 1. As seen in Figure 1, there is a positive trend in the mass change for all the concrete mixtures of $70 \mathrm{MPa}$ class. The mass gain can be attributed to water filling cracks, and to the mass of water used to precipitate the hydrated phase as ettringite [23]. 
For the 50 and $30 \mathrm{MPa}$ classes (with the exception of OC50 and OC30), a mass loss for SCC with different mineral admixtures was observed after four years of tests. When comparing SCCs of the same strength class at up to 720 days of immersion, unlike SCCPZ and SCCFA, the SCCLF mixtures did not show mass loss. At four years of immersion, the SCCLF presented the largest mass loss, especially in the $30 \mathrm{MPa}$ classes, with a difference of around 12\% compared to SCC30PZ and SCC30FA. The mass loss difference between SCCPZ and SCCFA was small (<1\%) for both 50 and $30 \mathrm{MPa}$ strength classes.

The ordinary concrete results showed better physical resistance against magnesium sulphate attack compared with SCC formulations with different mineral admixtures. During all the immersion times, no mass loss occurred for ordinary concrete formulations.

A visual inspection was carried out after four years of immersion in $5 \% \mathrm{MgSO}_{4}$ solution (Figures 2-4) to determine the state of the different samples. Obvious signs of degradation were observed in all specimens, with extensive spalling and cracking on surfaces. The most significant signs of degradation were observed in the SCC specimens, particularly those in 50 and $30 \mathrm{MPa}$ strength classes. The degree of deterioration in SCC30LF appeared to be highest, with greater physical expansion, a significant amount of spalling and cracking at corners and edges, and a remarkable loss of shape. Severe exterior damage was recorded in both SCC30FA and SCC30PZ. These concretes more or less kept their form, however their dimensions decreased considerably, with clearly deteriorated layers in exposed surfaces. For example, SCC30FA lost 4-6 mm on all sides and SCC30PZ lost 2-4 mm. Ordinary concrete samples underwent minimal change, mainly on the sides and the external surfaces. 


\subsubsection{Dimensional variation}

The length change of the samples immersed in magnesium sulphate solution is shown in Figures 5-7. The reference corresponds to the initial length just before immersion. Because the significant difference in results and the significant expansion of SCC50LF and SCC30LF, the length change of 50 and $30 \mathrm{MPa}$ class were presented in two figures. Figures 6(A) and 7(B) show the enlargement of vertical axis values (dimensional change). For the results of the $70 \mathrm{MPa}$ strength class (Figure 5), only OC70 showed expansion $(90 \mu \mathrm{m} / \mathrm{m})$ recorded after 1200 days of immersion. The low or the absence of expansion may be explained by the low value of water-binder ratio and the cement content in the concretes of this class. Indeed, according to Maltais [24], a reduction of w/c contributes to decrease the transport properties of the material and therefore limit the extent of degradation. Neville [25] added that, in high performance concrete there is limited pore space to accommodate the products of reactions with sulfate, namely, magnesium silicate hydrate and gypsum partly responsible on the expansion.

As can be seen from Figure 6, the expansion was registered starting from 560, 880 and 1320 days for OC50, SCC50LF and SCC50FA, respectively. At four years, expansion values of $1600 \mu \mathrm{m} / \mathrm{m}, 5085 \mu \mathrm{m} / \mathrm{m}$, and $28 \mu \mathrm{m} / \mathrm{m}$ were measured respectively for OC50, for SCC50LF and for SCC50FA. The expansion of OC50 was registered early than SCC50LF, however after four yours of immersion, the SCC50LF showed three times higher expansion than OC50. The same result was recorded for the $30 \mathrm{MPa}$ strength class concretes.

From the results of Figure 7, we can observe the continuous increase of expansion, especially for OC30 and SCC30LF with $2100 \mu \mathrm{m} / \mathrm{m}$ and $7870 \mu \mathrm{m} / \mathrm{m}$, respectively. The expansion was recorded starting from 520 days for OC30 and from 630 days for SCC30LF. The expansion of 
SCC30PZ and SCC30FA was measured starting between 1250 and 1290 days of immersion, with resulting values of $143 \mu \mathrm{m} / \mathrm{m}$ and $123 \mu \mathrm{m} / \mathrm{m}$, respectively. These observations emphasize that when SCC is exposed to magnesium sulphate attack, mixtures with limestone filler showed earlier and higher expansion than those containing natural pozzolan or fly ash. The expansion values of SCCPZ and SCCFA mixtures were negligible compared with those of the SCCLF mixtures.

By comparison between SCC and OC mixtures, the SCC prepared with natural pozzolan or fly ash consistently presented lower expansion than the OC. After four years of immersion, SCC incorporating limestone filler showed higher expansion. It is interesting to note that the expansion of OC mixtures occurred earlier than it did in SCCLF. However, after the four-year period, OC expansion was lower.

\subsubsection{Change of compressive strength}

The compressive strength change illustrated by the results of the control medium (fresh water) (C) and the magnesium sulphate (Mg) solution is shown in Figures 8-10. The four years compressive strength of SCC30LF was not measured because of the severe deterioration of samples in $5 \% \mathrm{MgSO}_{4}$.

As shown in Figures 8-10, compressive strength development was clearly influenced by the magnesium sulphate solution. There was a continuous increase in the compressive strength of specimens stored in fresh water versus a large decrease recorded for those stored in magnesium solution. This decrease was more marked for the $30 \mathrm{MPa}$ strength class, especially between 360 and 1440 days of immersion. 
If we consider that the reference corresponds to the initial values before immersion, it is clear that for $70 \mathrm{MPa}$ (Figure 8) and 50MPa classes (Figure 9), slight reductions in compressive strength values occurred after 1440 days (-4.4 MPa for SCC70LF, -6.1 MPa for OC50, -8.9 MPa for SCC50LF, -5.3 MPa for SCC50PZ and -5.2 MPa for SCC50FA). For the $30 \mathrm{MPa}$ class, the loss of strength was recorded starting at 90 days of immersion for OC30 (-20.7 MPa after 1440 days) and SCC30LF (complete deterioration at 1440 days). Late age strength loss was observed after 1440 days for SCC30PZ (-20.9 MPa) and SCC30FA (-21.5 MPa). In general, SCCPZ and SCCFA showed late loss of compressive strength compared with SCCLF or OC in the same compressive strength class. At four years of immersion, they showed almost the same values as OC. The SCCLF mixtures showed higher loss in compressive strength than the other concretes.

\subsubsection{Microstructural observations}

Specimens of the $30 \mathrm{MPa}$ concrete classes were examined by XRD after four years of immersion in magnesium sulphate solution. Measurements were performed starting at the surface layer $(0 \mathrm{~cm})$ and moving towards the interior $(0.8-1.0,1.8-2.0,2 .-3.0 \mathrm{~cm})$. Figure 11 presents the XRD spectra at different layers for each type of concrete. Patterns were obtained using an $\mathrm{X}$-ray diffractometer with $\mathrm{Cu} \mathrm{K} \alpha$ radiation and $2 \theta$ scanning, ranging between $5^{\circ}$ and $80^{\circ}$ of $2 \theta$.

The superposition of the spectra of different layers confirmed the presence of strong intensity peaks for gypsum formation at around 11.7 and $29.15^{\circ} 2 \theta$ for all concrete mixtures. Relatively strong peaks of ettringite were also detected on the surface layer of all concretes exposed to magnesium sulphate attack, especially at around 33.4 and $43.8^{\circ} 2 \theta$. In spite of the similarities 
between thaumasite and ettringite at around 9.1 and $16^{\circ} 2 \theta$, the XRD patterns confirmed the presence of thaumasite in the surface layer of OC30 and SCC30LF. Based on the peaks observed at 19.3 and $23.35^{\circ} 2 \theta$, the thaumasite peaks were very intense in SCC30LF compared with OC30 samples. It should be noted that the thaumasite was detected in the concrete specimens exposed to magnesium sulphate attack in a temperature maintained at $22 \pm 2{ }^{\circ} \mathrm{C}$. Previous studies have also reported the formation of small quantities of thaumasite (in pastes and mortars), even at room temperature [26,27]. Contrary to the OC30 and SCC30LF results, no trace of thaumasite was observed in SCC30PZ and SCC30FA. In comparing the data of each layer, the absence or negligible level of gypsum is notable in the $0.8 \mathrm{~cm}$ layer in all concrete mixtures. Ettringite was present in the other layers $(0.8-1.0 \mathrm{~cm}$, 0.8-2.0 cm, 0.8-3.0 cm) up to the core of specimens, but with fewer peaks, especially in SCC30PZ. The XRD results showed the presence of portlandite at around 18.1 and $34.1^{\circ} 2 \theta$, from $1.8 \mathrm{~cm}$ depth for OC30, from $0.8 \mathrm{~cm}$ depth for SCC30LF and from the 1.8-2 $\mathrm{cm}$ layer for SCC30PZ and SCC30FA. The portlandite was weak due to the significant consumption of calcium hydroxide in the magnesium sulphate reaction for OC and SCC30LF, and both pozzolanic and sulphate reaction in SCC30PZ and SCC30FA. There was no detectable trace of portlandite in the surface of all concrete samples, which indicates total leaching at this phase.

A small amount of brucite $\left[\mathrm{Mg}\left(\mathrm{OH}_{2}\right)\right]$ at around $37.95^{\circ} 2 \theta$ was evident in the surface layers of OC and SCC30LF. The peak due to brucite was always very weak in the surface layer of SCC30PZ and SCC30FA. The very low solubility of brucite favours the consumption of calcium hydroxide [27], which is related to the XRD peaks of portlandite. 
SEM-EDS analyses were conducted to qualitatively investigate the hydrate phases formed by sulphate attack. Figure 12 shows SEM micrographs of examined samples after four years of immersion in a 5\% magnesium sulphate solution. The micrographs (Figure 12 a-f) are taken from areas close to the surface layers of the samples. SEM observations of different degraded areas confirmed the presence of significant amounts of ettringite (Figure 12a and 12c) and gypsum (Figure 12b), as also noticed in XRD results.

EDS analysis of Figure 12d (OC30 sample) indicated that the crystals consisted mainly of Ca,

S, Si and C. Although there was a small amount of $\mathrm{Al}$ in the spectra, the product appeared to be thaumasite, because $\mathrm{Al}$ is replaced by $\mathrm{Si}$ in the thaumasite crystal structure [28]. The presence of thaumasite in the surface layer of OC30 appeared in the areas with a large amount of ettringite. This observation is an agreement with the results of KÖhler et al. [29], who reported that the presence of thaumasite is often preceded by the formation of ettringite, which considerably controls the rate of thaumasite formation. Figure 12e, which shows the SEM-EDS of SCC30LF, confirms the presence of the double layer consisting of brucite and gypsum. The presence of M-C-S-H (or Mg rich C-S-H) due to the magnesium sulphate attack was noticed through the EDS analysis of SCC30FA (Figure 12f). The M-C-S-H product was not detected by XRD because of its poor crystallinity.

\subsubsection{Penetration depth of degradation}

Sulphate profiles were performed from the surface to the core of each concrete sample, avoiding aggregates. Figure 13 presents the sulphate profile of the samples after four years of immersion in $5 \% \mathrm{MgSO}_{4}$. The variations of sulphur, magnesium, silicon, calcium and aluminium are presented to help understand the role of different mineral admixtures in the 
mechanism of degradation of OC and SCC mixtures. The results show that for OC30, the profile of Mg presents a maximum density at a very small surface region, presented at the approximate depth of $0.2 \mathrm{~mm}$ of brucite. The passage from the brucite to the gypsum was detected due to a maximum amount of sulphur of about $14 \%$ and a depth of $18 \mathrm{~mm}$. The gypsum amount decreased with depth, with a decrease in the peak of sulphur associated with increased calcium content and uniform concentration of silicon. The aluminium showed irregular concentration with a different maximum peak of ettringite, especially during the first $13 \mathrm{~mm}$. An increase in silicon was noted at around $14 \mathrm{~mm}$, and a similar concentration was maintained at $18 \mathrm{~mm}$ throughout the sample. The stabilisation in silicon concentration after increase, which is associated with the maximum amount of calcium at $18 \mathrm{~mm}$ depth, shows the presence of great amount of C-S-H, indicating the beginning of the safe area.

For SCC30LF, the presence of brucite in a slight exterior layer was indicated by a maximum peak of magnesium and a lower concentration of sulphur, silicon, and calcium. After reaching a depth of $0.2 \mathrm{~mm}$, the $\mathrm{Mg}$ contents dropped to the minimum throughout the rest of the specimen. The high levels of sulphur (about 10\%) revealed the presence of the surface double layer, followed by gypsum at a depth of $9 \mathrm{~mm}$. The decrease in sulphur by depth was associated with a decrease in calcium, and a stable amount of silicon indicated decreased gypsum concentration. Ettringite was revealed throughout the specimen by a maximum concentration of aluminium, especially at a $14 \mathrm{~mm}$ depth. The zone unaffected by the external solution was noticed from a $9 \mathrm{~mm}$ depth, and was characterised by the maximum amount of silicon and calcium.

Like the OC30 and SCC30LF specimens, SCC30PZ showed a maximum peak of magnesium in the surface layer, indicating brucite at a depth of $0.4 \mathrm{~mm}$. However, other peaks of 
magnesium were detected across the specimen, a result that corresponds to brucite being dispersed throughout the concrete. The sulphur patterns displayed a maximum concentration of about $4 \%$ and a depth of around $7.5 \mathrm{~mm}$, which indicated the presence of gypsum. With the exception of the low concentration of silicon in the first $2 \mathrm{~mm}$, the decrease in the sulphur patterns was accompanied by fluctuating peaks of silicon and calcium, with a small increase at $7 \mathrm{~mm}$. This explains the presence of an infected layer, as indicated by decalcification of the $\mathrm{C}-\mathrm{S}-\mathrm{H}$, as well as the presence of gypsum. A maximum concentration of aluminium was noted at around $2 \mathrm{~mm}$, accompanied by changes in sulphur and calcium, indicating the presence of a small amount of ettringite next to the gypsum.

The sulphate profile of SCC30FA was also started at the brucite cover, and was characterised by a maximum peak of magnesium. The significant breadth of the magnesium peak at a $2 \mathrm{~mm}$ depth was associated with a low concentration of calcite and aluminium. However, the sulphur initially presented a low value (at $0.4 \mathrm{~mm}$ depth), followed by a maximum peak through the rest of the $2 \mathrm{~mm}$ depth, as shown in the case of magnesium. The silicon also showed a low concentration in the exterior surface, increasing after $1 \mathrm{~mm}$ depth, with maximum peak at around $2 \mathrm{~mm}$. These changes indicated the major deterioration area with an evident brucite cover (around $0.4 \mathrm{~mm}$ ) followed by an M-S-H layer interblended by gypsumettringite. The relatively high concentration of sulphur decreased with depth, stabilizing at a low value after about $7 \mathrm{~mm}$ into the specimen. This decrease was associated with a stable concentration of silicon. The line profile for Ca fluctuated but increased at a low rate toward the interior of the bar. Calcium increased at a low rate toward the $7 \mathrm{~mm}$ depth, indicating that the zone was affected by decalcification of the C-S-H. 
A complementary analysis of the microstructure was performed on the degraded layers (0-7 mm zone for SCC30PZ and SCC30FA, 0-18 mm zone for OC30 and 0-9 mm for SCC30LF). Figure 15 presents the changes in the phase assemblage across the samples of the element ratios $\mathrm{S} / \mathrm{Ca}$ as a function of $\mathrm{Al} / \mathrm{Ca}$. The plots of $\mathrm{S} / \mathrm{Ca}$ vs. $\mathrm{Al} / \mathrm{Ca}$ (Figure 14) suggest that the $\mathrm{S} / \mathrm{Ca}$ and $\mathrm{Al} / \mathrm{Ca}$ ratios of 1 and 0 , respectively, correspond to gypsum. The ettringite phase has $\mathrm{S} / \mathrm{Ca}=0.5$ and $\mathrm{Al} / \mathrm{Ca}=0.33$, monosulphoaluminate has $\mathrm{S} / \mathrm{Ca}=0.25$ and $\mathrm{Al} / \mathrm{Ca}=0.5$.

The microanalyses of the degraded layers of concrete samples confirmed the results of the sulphate profile. Figure 14 shows the presence of an important amount of the C-S-H phase partly intermixed with ettringite in SCC30LF and OC30. The C-S-H phase was rarely seen in the degraded zones of SCC30PZ and SCC30FA. A small concentration of ettringite was noted in SCC30PZ, but no trace of this element was found in the phase assemblage of SCC30FA.

Gypsum was identified in OC30 and seemed to appear in smaller amounts in the SCC30LF mixture. Contrary to the sulphate profile results, the SCC30PZ and SCC30FA analyses showed an absence of gypsum in the degraded layer. Portlandite was detectable in the SCC30LF concrete, but not in OC30, SCC30PZ and SCC30FA; these results were in agreement with those of the XRD analysis. Higher amounts of monosulphoaluminate were detected in SCC30PZ and SCC30FA, which is partly attributable to the high percentage of alumina in the chemical composition of natural pozzolan and fly ash. It can also be attributed to the fact that the monosulphoaluminate in these two concrete specimens had not yet transformed into ettringite. According to Schmidt [30], ettringite is formed by a reaction between sulphate ions and aluminates (sulphoaluminate or carboaluminate). When the reserve in aluminate is exhausted, ettringite crystallization stops and sulphate ions react with calcium ions to form gypsum. 


\section{Summary and discussion}

A comparison of the results of different compressive strength classes showed increased mass loss, expansion and compressive strength loss from the higher to the lower strength classes. The lower compressive strength concretes (30 MPa) showed weaker performance against magnesium sulphate attack. Indeed, according to Siad et al. [31] and Guillon et al. [32], the volume and connectivity of the porous network decrease when the water/binder ratio decreases, therefore making the penetration of aggressive agents more difficult.

The difference between the results obtained for SCC and OC relates to the time of exposure and the nature of the mineral admixture. During more than three years of immersion, the OC mixtures showed greater expansion and compressive strength loss. The early compressive strength loss in OC mixtures is correlated with the major diffusion of sulphur through the concrete, leading to a maximum amount of gypsum manifested by early expansion. The lower physical damage of OC specimens after four years of immersion may be related to the gradual expansion, with a gradual reduction in the cohesiveness of the hydrated cement paste. This conclusion is supported by the presence of significant amounts of C-S-H, even in the infected exterior layer showed beyond the brucite film.

The positive behaviour of SCC mixtures in the early state of immersion can be attributed to the denser matrix of these concretes compared with OC. The large amounts of natural pozzolan, fly ash and limestone filler in SCC paste promoted a denser microstructure, which contributed to decreased diffusion of aggressive ions like magnesium sulphate ions [33]. Indeed, according to Bonen and Cohen [3,4], magnesium sulphate attack has a progressive diffusion process in Portland cement paste involving several stages including the conversion 
of portlandite to brucite and gypsum, the conversion of $\mathrm{C}_{3} \mathrm{~A}$, hydrated calcium aluminate, and monosulphate to secondary ettringite, and the decalcification of C-S-H to form M-S-H.

By comparing concretes of the same strength class,_the results showed that the SCCLF experienced greater mass loss, visual damage, expansion and compressive strength loss. SCCPZ and SCCFA results showed lower (or absent) expansion, accompanied by significant mass loss, physical damage and compressive strength loss. The low resistance of SCCLF formulations against $\mathrm{MgSO}_{4}$ attack is consistent with the results of Seung et al. [34] and Tosun et al. [28], who observed that high limestone replacement rates negatively affect the sulphate resistance of cement mortars. It is important to note the evolution of results by time; the lower performances of SCCLF were recorded extremely late. A good correlation between expansion results, mass loss, physical damage and compressive strength loss was clear in the case of SCCLF. According to Liu et al. [35], the expansion of mortar destroys the microstructure and causes a progressive loss of strength and mass. The most probable cause of the large expansion in SCCLF mixtures was the presence of gypsum and especially thaumasite after long-term exposure to $\mathrm{MgSO}_{4}$. In spite of the presence of thaumasite in the OC mixtures, XRD analysis showed very intense thaumasite peaks in SCC30LF. Also, the carbonate sources and the calcite available in the case of SCCLF suggested a higher thaumasite component. Schmidt [30] reported that the amount of thaumasite formed during sulphate interaction significantly influences the damage of the concrete structure, and concluded that small amounts of thaumasite observed in pores or cracks have no significant impact on strength loss.

In case of SCCFA and SCCPZ, the microstructure study indicated that the brucite layer in SCCPZ and SCCFA was two times thicker than in the SCCLF and OC specimens. Brucite 
formation on the specimen faces and the denser microstructure promoted by the pozzolanic reaction protected the samples from penetration of magnesium sulphate ions [36], slowing the damage process of natural pozzolan and fly ash SCC mixtures. After long-term immersion, the mass loss of the SCCPZ and SCCFA mixtures was correlated with physical damage and compressive strength loss. However, it was observed that the lower values of expansion did not correlate with the important physical damage. Moreover, the microstructure study of SCCFA and SCCPZ showed the presence of areas affected by the decalcification of C-S-H just under the brucite layer, especially in the interfacial transition zone around the aggregate. This suggests that, after a long period of time, the magnesium solution penetrated through the damaged interfacial transition zone (ITZ) in the external layer causes the decrease in dimensions by surface loss. This conclusion is also supported by the deterioration method of SCCPZ and SCCFA samples viewed by visual inspection and SEM profile images. Visual damage showed starting at the exterior and progressing into the disintegration of aggregate and leaching of the paste. The SEM profile images showed several lines of rich magnesium along the exterior damaged layer. This conclusion is consistent with the results of Kunther et al. [37], who worked on a comparison between CEMI and CEMIIII/B cement mortar bars immersed in magnesium sulphate solution. They found that for CEMI III binder, surface erosion of mortar specimens is the dominant deterioration mechanism.

In the microstructure study, the presence of a large amount of monosulphoaluminate corresponded to the absence of portlandite, the low concentration of ettringite, and the rare CS-H phase in the infected layers of SCCPZ and SCCFA. According to Schmidt [30] the participation of portlandite is the one possible cause of ettringite formation from monosulphate during sulphate attack. Hossain and Lachemi [38] added that the consumption of $\mathrm{Ca}(\mathrm{OH})_{2}$ by the pozzolanic reaction causes $\mathrm{Mg}^{2+}$ actions to react directly with the C-S-H 
gel, converting it to M-S-H. This is also in agreement with the presence of M-S-H directly under the brucite layer in the sulphate profile of SCCPZ and SCCFA samples.

\section{Conclusions}

This paper aims to contribute to a better understanding of the effects of the nature of mineral admixtures on the behaviour of SCC mixtures in magnesium sulphate environments for an immersion period of four years by evaluating mechanical, physical, chemical, mineralogical and microstructural deterioration of concrete samples. Three strength classes (30 MPa, 50 $\mathrm{MPa}$ and $70 \mathrm{MPa}$ ) and three mineral admixtures (limestone filler, fly ash and natural pozzolan) were studied. The following conclusions were drawn from the study:

1. Physical damage, expansion and compressive strength loss due to $\mathrm{Mg}_{2} \mathrm{SO}_{4}$ attack, increased from the higher to the lower strength classes of concretes. SCC mixtures containing limestone filler presented the highest physical deterioration, especially in the $30 \mathrm{MPa}$ class, with $18 \%$ mass loss. The $30 \mathrm{MPa}$ classes of SCC with natural pozzolan and fly ash also showed remarkable deteriorated surfaces, with mass loss ranged between 4 and 5\%. No mass loss was recorded for the ordinary concrete mixtures.

2. After four years of exposure to magnesium sulphate solution, the SCC with limestone presented a very advanced expansion, especially for concretes in the $30 \mathrm{MPa}$ strength class, with values $(7870 \mu \mathrm{m} / \mathrm{m})$ too higher than in the OC mixtures $(2100 \mu \mathrm{m} / \mathrm{m})$. Minor expansion was recorded for all SCCs containing fly ash or natural pozzolan with $143 \mu \mathrm{m} / \mathrm{m}$ and $123 \mu \mathrm{m} / \mathrm{m}$, respectively. 
3. All concrete formulations showed a decrease in compressive strength, especially for $30 \mathrm{MPa}$ strength classes with loss of 20.7 MPa for OC30, 20.9 MPa for SCC30PZ and 21.5 MPa for SCC30FA. The greatest loss was observed in the SCCLF formulations, with complete deterioration of SCC30LF.

4. A good correlation between mass loss, physical damage, expansion, and compressive strength loss results were found in the case of SCCLF. Expansion of SCCLF due to the presence of gypsum and thaumasite after long-term exposure to $\mathrm{MgSO}_{4}$ was the most probable cause of the sample weakness. For SCCPZ and SCCFA mixtures, the mass loss was linked to the physical damage and compressive strength loss; however, the results of expansion with lower values did not correlate with the important physical damage. Severe exterior deterioration of SCCPZ and SCCFA was observed due to surface erosion.

5. Microstructure analysis using SEM-EDS and XRD showed significant changes in the degraded zone. Formation of gypsum and ettringite was found in different amounts in all concrete mixtures. The formation of thaumasite was detectable in OC and occurred in higher amounts in SCCLF mixtures. Higher C-S-H decalcification occurred in SCCPZ and even more so in SCCFA.

6. The results of the sulphate profile, which used SEM-EDS to determine variations of sulphur, magnesium, silicon, calcium and aluminium in concrete samples, were consistent with those of the XRD analysis. After four years of immersion in 5\% $\mathrm{MgSO}_{4}$ solution, the expansion of OC mixtures depended on the amount of gypsum and ettringite, the degradation of SCCLF was related to the amount of thaumasite, and the deterioration of SCC containing natural pozzolan or fly ash was based on the amount of C-S-H replaced by M-S-H in advanced stages of immersion. 


\section{References}

[1] Yildirim K, Sumer M. Effects of sodium chloride and magnesium sulfate concentration on the durability of cement mortar with and without fly ash. Composites: Part B 2013; 52:5661.

[2] Golop R.S, Taylor H.F.W. Microstructural and microanalytical studies of sulfate attack, III. Sulfate resisting Portland cement: reaction with sodium and magnesium sulphate solutions. Cement and concrete research 1995; 25: 1581-1590.

[3] Bonen D, Cohen M. D. Magnesium sulfate attack on Portland cement paste - I. microstructural analysis. Cement and concrete research 1992; 22:169-180.

[4] Bonen D, Cohen M. D. Magnesium sulfate attack on Portland cement paste - II. Chemical and mineralogical analyses. Cement and concrete research. 1992; 22:709-718.

[5] Sumer M. Compressive strength and sulfate resistance properties of concretes containing Class F and Class C fly ashes, Construction and Building Materials 2012; 34:531-536.

[6] Shannag M.J, Shaia H. A. Sulfate resistance of high-performance concrete. Cement and Concrete Composites 2003; 25:363-369.

[7] Jaturapitakkul C, Kiattikomol K, Tangchirapat W, Saeting T, Evaluation of the sulfate resistance of concrete containing palm oil fuel ash. Construction and Building Materials 2007; 21: 1399-1405.

[8] Siddique R. Properties of concrete made with volcanic ash. Resources, Conservation and Recycling 2012; 66:40-44.

[9] Sharif M. B, Anjum A, Tahir M. A, Yousaf M. Performance of Pozzolanic Concrete Using Different Mineral Admixtures. Pak. J. Eng. \& Appl. Sci. 2013; 12: 73-81.

[10] Uysal M, Sumer M. Performance of self-consolidating concrete containing different mineral admixtures. Construction and Building Materials 2011; 25: 4112-4120. 
[11] Hassan A, Bin Mahmud H, Jumaat M. Z, Alsubari B, Abdulla A. Effect of Magnesium Sulphate on Self-Consolidating Concrete Containing Supplementary Cementitious Materials. Advances in Materials Science and Engineering 2013, Article ID 232371.

[12] Scrivener K.L. Backscattered electron imaging of cementitious microstructures: understanding and quantification. Cement and concrete Composites 2004; 26:935-45.

[13] European standards EN 197-1. Cement. Composition, specifications and conformity criteria for common cements. EN 197-1 ; 2012.

[14] American Society for Testing and Materials. Standard specification for Portland cement. ASTM C150-12; 2012.

[15] European standards EN 450. Fly ash for concrete - definitions, requirements and quality control. EN 450; 2012.

[16] Organization of the French standardization system. Additions for concrete - Limestone additions - Specifications and conformity criteria. Standard Number: NF P18-508; 2012.

[17] Sedran T, De Larrard F. BetonlabPro 2, ComputerAided MixDesign Software. Presses de l’Ecole Nationale des Ponts et Chaussées, Paris, France; 2000.

[18] Dreux G, Festa J. Nouveau guide du béton. Eyrolles édition, France; 1995.

[19] Association Française de Génie Civil (AFGC). Interim recommendations for use of selfconsolidating concrete; July 2002.

[20] American Society for Testing and Materials. Standard test method for length change of hydraulic-cement mortars exposed to a sulfate solution. ASTM C1012-04; 2004.

[21] Mehta PK. Evaluation of sulfate resisting cements by a new test method. J ACI 1975; 72(40):573-5.

[22] Bonavetti, V.L., Rahhal V.F, Irassar E.F. Studies on the carboaluminate formation in limestone filler- blended cements. Journal Cement and Concrete Research 2001; 33:853-859. 
[23] Khelifa R, Brunetaud X, Chabil H, Al-Mukhtar M. Consequences mecaniques de l'attaque sulfatique externe sur les betons autoplaçants. Sci Technol 2008; 28:23-8.

[24] Maltais Y, Samson E, Marchand J. Predicting the durability of Portland cement systems in aggressive environments - laboratory validation. Cement and Concrete Research 2004; 34: 1579-1589

[25] Neville A. The confused world of sulfate attack on concrete, Review. Cement and Concrete Research 2004; 34:1275-1296.

[26] Lee ST, Hooton RD, Jung HS, Park DH, Choi CS. Effect of limestone filler on the deterioration of mortars and pastes exposed to sulfate solutions at ambient temperature. Cement and concrete research 2008; 38:68-76.

[27] Skaropoulou A, Sotiriadis K, Kakali G, Tsivilis S. Use of mineral admixtures to improve the resistance of limestone cement concrete against thaumasite form of sulfate attack. Cement \& Concrete Composites 2013; 37: 267-275.

[28] Tosun K, Felekoglu B, Baradan B, Akın Altun I. Effects of limestone replacement ratio on the sulfate resistance of Portland limestone cement mortars exposed to extraordinary high sulfate concentrations. Construction and Building Materials 2009; 23: 2534-2544.

[29] KÖhler S, Heinz D, Urbonas L. Effect of ettringite on thaumasite formation. Cement and Concrete Research 2006; 36: 697-706.

[30] Schmidt T. Sulfate Attack and the Role of Internal Carbonate on the Formation of Thaumasite. Ecole polytechnique fédérale de Lausanne. PhD Thèses ; 2007.

[31] Siad H, Kamali-Bernard S, Mesbah H.A, Escadeillas G, Mouli M, Khelafi H. Characterization of the degradation of self-consolidating concretes in sodium sulfate environment: Influence of different mineral admixtures. Construction and Building Materials 2013; 47:1188-1200. 
[32] Guillon E, Moranville M, Kamali S. Characterization of the mechanical damage of a chemically degraded cement paste. Mater Struct/Matér Constr 2006; 39(4):401-409.

[33] Siad H. Influence du type d'addition minérale sur le comportement physicomécanique et sur la durabilité des bétons autoplaçants. PhD Thèses, INSA de Rennes (France); 2010.

[34] Seung Tae Lee a, Robert Doug. Hooton b, Ho-Seop Jung c, Du-Hee Park d, Chang Sik Choi. Effect of limestone filler on the deterioration of mortars and pastes exposed to sulfate solutions at ambient temperature. Cement and Concrete Research 2008; 38: 68-76.

[35] Liu S, Yan P, Feng J. Effect of Limestone Powder and Fly Ash on Magnesium Sulfate Resistance of Mortar. J. of Wuhan University of Technology-Mater. Sci. Ed 2010; 700-703.

[36] Biricik H, Türker F, Berktay I. Resistance to magnesium sulfate and sodium sulfate attack of mortars containing wheat straw ash. Cement and Concrete Research 2000; 30(8): 1189-1197

[37] Kunther W, Lothenbach B, Scrivener K. L. Deterioration of mortar bars immersed in magnesium containing sulfate solutions. Materials and Structures (2013) 46:2003-2011 [38] Hossain K.M.A, Lachemi M. Performance of volcanic ash and pumice based blended cement concrete in mixed sulfate environment. Cement and Concrete Research 2006; 36: $1123-1133$. 